\title{
Towards Dual and Three-Channel Electrical Architecture Design for More-Electric Engines
}

\author{
Qiyang Zhang, Michal Sztykiel, Patrick Norman, and Graeme Burt University of Strathclyde
}

\begin{abstract}
In recent years, the More-Electric Aircraft (MEA) concept has undergone significant development and refinement, striving towards the attainment of reductions in noise and $\mathrm{CO} 2$ emissions, increased power transmission efficiency and improved reliability under a range of flight scenarios. The More-Electric Engine (MEE) is increasingly being seen as a key complementary system to the MEA. With this concept, conventional engine auxiliary systems (i.e. fuel pumps, oil pumps, actuators) will be replaced by electrically-driven equivalents, providing even greater scope for the combined aircraft and engine electrical power system optimisation and management. This concept, coupled with the extraction of electrical power from multiple engine spools also has the potential to deliver significant fuel burn savings. To date, single or dual channel electrical power generation and distribution systems have been used in engines and aircraft. However, with the increasing electrification of flight-critical engine auxiliaries along with the requirement for greater load transfer flexibility, a threechannel architecture should be considered.
\end{abstract}

This paper investigates potential concepts for a three-channel power system architecture in an MEE system. The paper considers issues such as architecture layout and key technologies that may be considered for MEE architecture. Using an extensive database of public domain MEA/MEE power system component failure rates, a detailed fault tree analysis is then presented. This provides a quantitative comparison of dual channel and three-channel architecture candidates under the pertinent failure modes as well as showing the impact of common architecture features on system reliability and robustness. Finally, the paper concludes with a discussion of the ring busbar topology operation and power electronics technology requirements that could successfully implement a flexible and robust three-channel architecture for MEE systems.

\section{Introduction}

The key characteristics of a More-Electric Engine (MEE) are the increased electrification of engine auxiliary systems and the increased flexibility of generation on different engine shafts [1]. Having an MEE system rather than the conventional engine system for MEA should offer a better fuel efficiency and lower noise emission [2]. Whilst proposed MEE systems are still quite diverse in concept, they typically feature the replacement of the conventionally gearbox-driven technologies such as the hydraulic/mechanical thrust reverser actuation, fuel and oil pump systems with their electrical equivalents. Furthermore, an additional Low-Pressure (LP) shaft-driven generator embedded on the turbine section of the engine could be featured in order to complement the more conventional High-Pressure (HP) shaft-driven

Page 1 of 11 generators. Figure 1 shows an example prototype MEE system, with physical locations of novel hardware electrical components displayed.

The aim of this paper is to highlight the characteristics of the dual channel and three channel electrical power systems for MEE applications. Due to the increased electrical load demand on MEE, it requires a reliable and flexible transformation and distribution of electrical power.

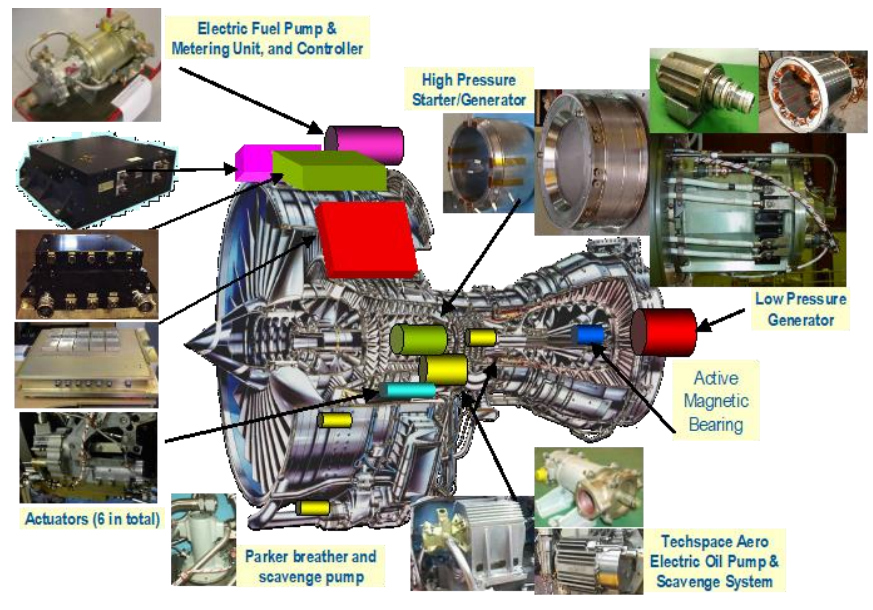

Figure 1. A concept of More Electric Engine from ESVR demonstrator [1]

Firstly, this paper reviews the potential electrical devices that may be suitable for a multi-channel architecture. The characteristics and features of those electrical components such as generators, busbar topologies, converters and loads are highlighted.

Lastly, a reliability analysis and comparison is presented between dual and three channel electrical power architectures. The performed comparison concludes an overview of multi-channel electrical power system architectures for future MEE and can be used to evaluate the considerations of EPS architecture design.

\section{Dual-Channel and Three-Channel Systems}

Currently, single and dual-channel electrical power generation systems are employed on most aircraft engine electrical systems [3,4]. A singlechannel MEE power system will have a higher risk of an in-flight shutdown, as the single channel electrical power system has no redundancies in case of component failure, and may not be sufficiently reliable for such a flight critical system. Therefore, dual-channel or 
three-channel systems should be considered for MEE applications to attain the desired level of redundancy and load management.

\section{Dual Channel Architecture}

In a dual-channel electrical architecture, both channels would share the supply to essential loads, improving the reliability and flexibility of the system. For a dual-channel architecture, each one of the essential auxiliary systems of the engine would be conducting with two feeding lines. At the same time, each of the two channels will supply and distribute power to various non-essential loads. In the abnormal situation of a single fault or a minor power system failure, the dualchannel architecture should be able to isolate the faulted section of network and shed the non-essential loads to ensure continued unrestricted supply to critical loads, facilitating safe flight.

\section{Three-Channel Architecture}

The concept of the three-channel architecture has been proposed in accordance with the increasing electrification requirements of the MEA/MEE auxiliary systems [1,3]. In a dual-channel architecture, two main engine-driven generators are typically employed. In the case of three-channel electrical architectures, the extra power source can be obtained from a different shaft which would operate in isolation from the two remaining power sources. The main advantage of the threechannel system is higher reliability of system operation, as well as higher level of flexibility for load management during normal operating conditions. With a minor or single fault scenario, a threechannel architecture should allow the isolation of a failed channel section while maintaining a non-interrupted supply to all essential loads.

\section{Potential Features of Multi-Channel System}

This section is used to describe the layout of the candidate threechannel electrical architecture and its potential features. The following section defines the layout of the architecture as:

1. Power generation: generators and storage used to supply electrical power.

2. Voltage levels of the entire potential electrical power system.

3. Potential busbar topologies.

4. Critical electronic components: ATRU, rectifier and inverter.

5. Essential MEE loads, such as fuel pumps, oil pumps and thrust reverser actuation system.

\section{Potential Generation/Sources in MEE}

Some current MEA designs use two variable frequency AC synchronous generators per engine [5]. This type of generator is able to operate at a frequency range of $360 \mathrm{~Hz}$ to $800 \mathrm{~Hz}$ [6]. In order to distribute the power from the generator into an $\mathrm{AC}$ bus of $230 \mathrm{~V} \mathrm{ac}$ at $400 \mathrm{~Hz}$, a power electronics component such as an active converter is needed at the busbar terminals. Additionally, a generator control unit (GCU) may be required to supervise the generator and converter and to support the terminal voltage regulation. Figure 2 illustrates the different types of generator that may be utilised in MEE designs.

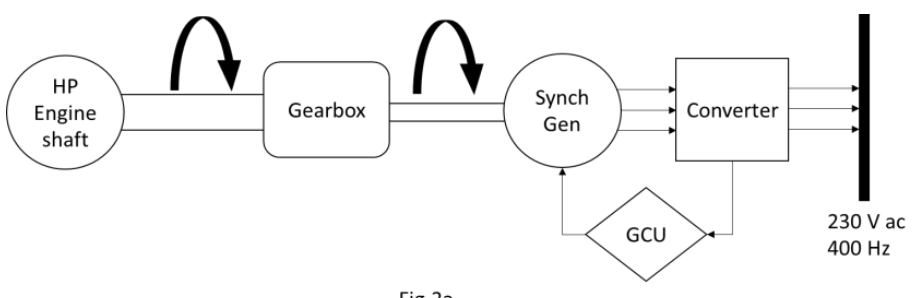

Fig.2a

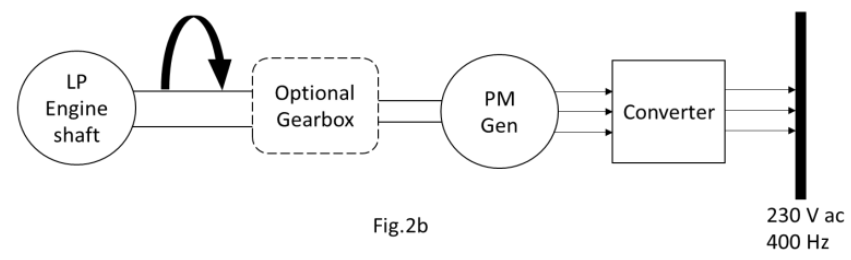

Figure 2. a) Variable Frequency (VF) synchronous generator system. b) PM generator

Wound field synchronous machines or permanent magnet (PM) machines are commonly proposed for the starter/generator in aircraft engines [7], although switched reluctance technologies have also been considered. These machines may either be gearbox driven from the main spool or directly embedded within the engine to facilitate the removal of the associated gear box components [1, 8, 9 ]. Given the wider speed range of the LP shaft in comparison to the HP shaft, the associated generator typically requires a power electronic conversion stage to achieve a network-compatible output voltage and frequency. Table 1 shows candidate generator designs for an MEE system. PM and SR technologies show good promise, although the entire mass of the system, including gearbox and electrical filtering components needs to be considered when making technology trades.

Table 1. Candidate generation source for EPS architecture design

\begin{tabular}{|c|c|c|c|c|}
\hline Generator type & $\begin{array}{c}\text { Converter } \\
\text { required }\end{array}$ & $\begin{array}{c}\text { Power } \\
\text { rating }\end{array}$ & $\begin{array}{c}\text { Gearbox } \\
\text { required }\end{array}$ & $\begin{array}{c}\text { GCU } \\
\text { required }\end{array}$ \\
\hline $\begin{array}{c}\text { Wound field } \\
\text { starter/generator }\end{array}$ & $\begin{array}{c}\text { Yes; } \\
\text { DC or } \\
\text { AC-400Hz } \\
\text { operation }\end{array}$ & $250 \mathrm{kVA}$ & $\begin{array}{c}\text { Yes, } \\
\text { accessory } \\
\text { gearbox }\end{array}$ & Yes \\
\hline $\begin{array}{c}\text { PM } \\
\text { starter/generator }\end{array}$ & Yes & $250 \mathrm{kVA}$ & $\begin{array}{c}\text { Youpling } \\
\text { with an } \\
\text { integral } \\
\text { gearbox }\end{array}$ & No \\
\hline $\begin{array}{c}\text { Switched- } \\
\text { Reluctance } \\
\text { starter/generator }\end{array}$ & Yes & $250 \mathrm{kVA}$ & Optional & No \\
\hline
\end{tabular}

\section{Energy Storage System (ESS)}

Energy storage systems provide an emergency supply of electrical energy following an unexpected loss of power from the generators. High voltage battery systems are being proposed for MEE applications, with the authors in [10] proposing a battery bank interfaced directly to a 270 VDC HVDC bus through a bidirectional 
DC-DC converter. Lithium-based battery chemistries are commonly considered for MEA/MEE applications owing to their higher energy density, higher power efficiency and lighter mass than the nickelcadmium and lead acid battery technologies [11].

\section{Voltage characteristics and levels}

Multi-channel electrical architectures could potentially utilise different operational voltage levels and frequencies throughout the network. Often, power electronic converters are required to provide a system interface between these disparate points in the network, for example, between the output of the generators and the main distribution bus. All the electrical loads across the airframe, would typically be fed by an $115 / 230 \mathrm{~V}$ ac distribution busbar (with further voltage/frequency conversion taking place on the airframe power architecture) [12]. In this paper, it is assumed that an airframe requires each generator interfaced with an active converter to supply a dedicated generation bus, so that on-engine loads will have a minimum impact on the supply quality of airframe loads. As a consequence, the on-engine HVDC busbars required to supply the essential auxiliary engine loads, are interfaced via passive converters, i.e. Auto Transformer Rectifier Units (ATRU). Due to safety and weight drivers [13], high voltage/low current ratings are utilised for auxiliary loads where possible. Additionally, the location of ETRA, which requires longer cable feeds, may encourage the use of HVDC distribution in order to reduce cable weight. Table 2 shows candidate voltage levels proposed for the electrical power structure for MEE.

Table 2. Voltage levels of candidate MEE EPS architecture

\begin{tabular}{|c|c|c|}
\hline Voltage level & Sections & Power Outgoing to \\
\hline $\begin{array}{l}\mathrm{VF} / \mathrm{CF} \text { to } \\
230 \mathrm{Vac}\end{array}$ & Power Generation & - Main distribution bus \\
\hline $\begin{array}{c}230 \mathrm{Vac} \\
400 \mathrm{~Hz}\end{array}$ & Main distribution bus & $\begin{array}{l}\text { - } \begin{array}{l}\text { Fuselage loads } \\
\text { - }\end{array} \begin{array}{l}\text { HVDC distribution } \\
\text { bus }\end{array} \\
\end{array}$ \\
\hline $\pm 270 \mathrm{Vdc}$ & HVDC distribution bus & $\begin{array}{l}\text { - } \\
\text { Engine auxiliaries } \\
\text { level } \\
\text { - } \quad \text { LVDC level } \\
\end{array}$ \\
\hline $115 \mathrm{Vac}$ & $\begin{array}{l}\text { Engine auxiliary } \\
\text { systems level }\end{array}$ & 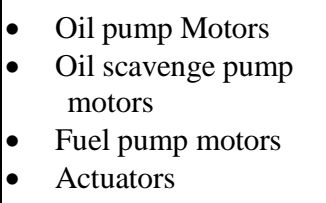 \\
\hline $28 \mathrm{Vdc}$ & LVDC level & $\begin{array}{ll}\text { - } & \text { Energy storage } \\
\text { - } & \text { FADEC } \\
\text { - } & \text { Fuel ignition }\end{array}$ \\
\hline
\end{tabular}

\section{Busbar arrangement in the $\mathrm{MEE}$ architecture}

The busbar configuration within an MEE system is essential to maximising load management flexibility and architecture redundancy whilst minimising weight. This section presents candidate MEE busbar arrangements, which are further analysed from a reliability perspective later in the paper.

Each of identified busbar arrangements below has a unique set of advantages for aircraft EPS architecture. Note that the single busbar arrangement is not considered in this paper, as it lacks flexibility and reliability for the system redundant operation [14]. If any component

Page 3 of 11 in the single bus arrangement fails, the distribution system will be unable to remain operational. Hence, this paper will focus on more advanced busbar arrangements suitable for the flight critical nature of the MEE power system.

\section{Sectionalised Bus}

The sectionalised bus is a common busbar arrangement that is used in aircraft electrical systems [15]. It divides the electrical system architecture into individual channels by using contactors to separate the busbar into individual sections. Figure 3 shows an example of the three-channel architecture for MEE with a sectionalised busbar.

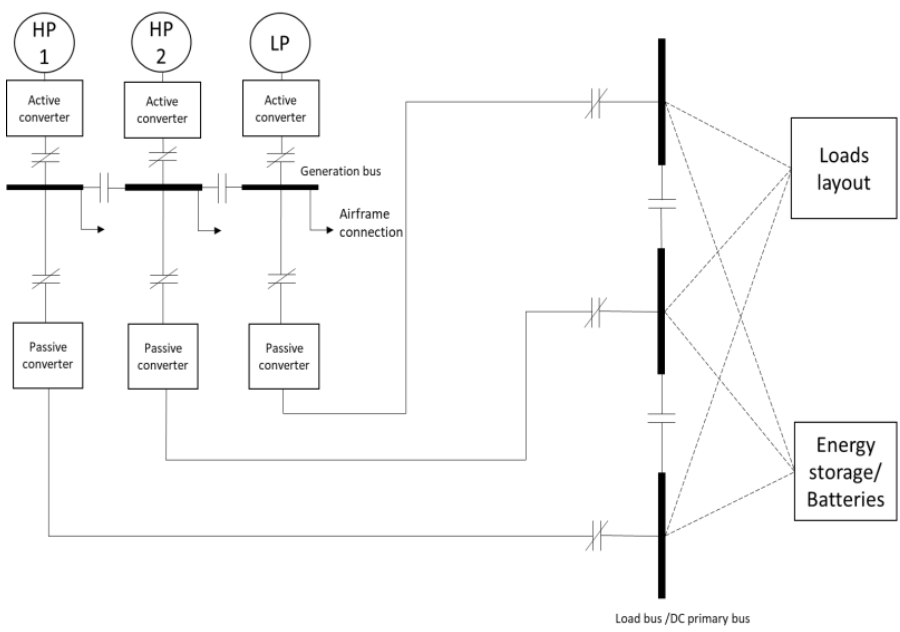

Figure 3. Three-channel architecture with sectionalised bus arrangement

The arrangement will significantly have a higher overall operational reliability than a single bus arrangement. Under normal operating conditions, the contactors on the sectionalised bus will be in an open state. This allows isolated operation of individual channels so that the occurrence of a single electrical fault will not disrupt the supply to all channels. Under abnormal operating conditions, for example, after a fault has occurred and the failed component of network section has been removed by protection device operation, [14], the system will be reconfigured in accordance with a dedicated power management strategy to restore power flow to as many loads as possible. However, if failures exist in multiple sections of the architecture, then maintaining the functionality of the electrical system may become unfeasible. Consequently, non-critical load shedding may be necessary to maintain the continuous supply to essential loads.

\section{Ring Bus}

A ring bus configuration is a commonly used topology in shipboard electrical distribution systems and it is commonly configured with sectionalising breakers [16]. Figure 4 illustrates an example concept of a three-channel MEE architecture adopting a ring bus topology. 


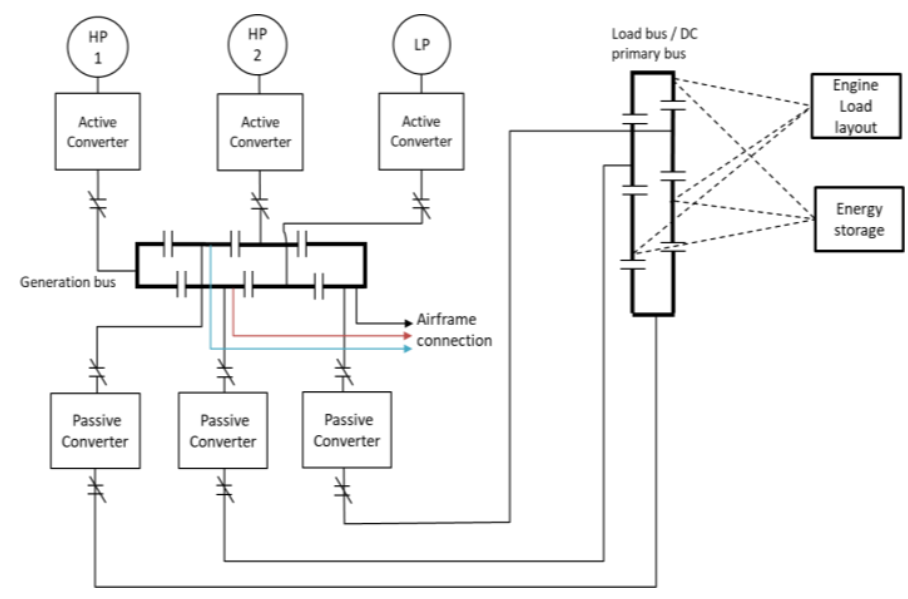

Figure 4. Three-channel architecture with ring bus configuration

In an example of a ring bus arrangement, a power source supplies a feed bus. This feed bus is then connected to two receiving buses respectively, with contactors in place to provide the necessary isolation between buses. The electrical loads are supplied from the receiving buses. The physical location of the ring bus is flexible, for example it can be mounted around the shape of the engine. From the three receiving buses, power feeds into the critical engine loads such as the electric oil pumps for engine lubrication system, fuel system and ETRAs can be established. The ring bus configuration contains redundancy for each critical load supplied. As a result, a first-order failure such as an active fault or breakdown of insulation in a CB will not cause this configuration to fail [14], which should significantly increase the flexibility and reliability of the power flow to critical loads. The main disadvantage of the ring configuration is the limitation of circuit positions; six bus terminals would usually be the maximum for a ring bus topology [17], as a larger number of bus terminals could increase the difficulty of re-configuration.

\section{Breaker-And-A-Half with Sectionalised Bus}

The Breaker-And-A-Half (BAAH) busbar arrangement contains two parallel busbars that are connected by several conducting bays [16]. This concept has been developed for power substation and shipboard applications [14]. In each conducting bay, interconnections to either upstream sources or downstream loads can be utilised. An example three-channel BAAH network configuration is shown in Figure 5.

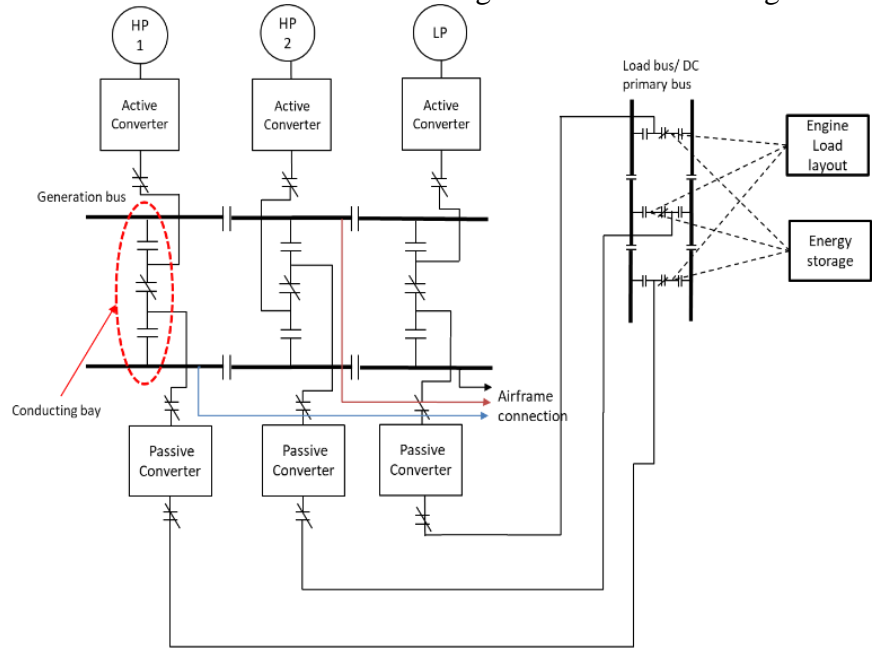

Figure 5. Three-channel architecture with breaker and a half bus configuration
Three contactors are typically employed in each conducting bay. One of these is the main tie $\mathrm{CB}$, which is located in the centre of the power line. The tie CB can contribute to either the connection or isolation of both lines in the conducting bay. The other two contactors facilitate the connection or disconnection of power from the corresponding upstream and downstream buses. In this manner, the BAAH busbar topology ensures that each of the distribution lines is protected by two contactors $[12,13,14]$.

The BAAH configuration can provide a high level of EPS redundancy for MEE applications. By using sectionalised contactors on the two parallel busbars, channels can be completely isolated under the normal operation [14]. However, the increased number of electrical components may cause higher maintenance cost and system weight. Similar to a ring bus arrangement, this configuration is resilient to a single component failure.

Each of the example busbar arrangements presented in this section utilise only a single type of bus layout for the entire EPS architecture. However, a combination of various busbar topologies could also be considered for an MEE architecture. For example, a particular design could employ a high-reliability BAAH configuration for $230 \mathrm{~V}$ ac main distribution, while at the same time utilising a ring bus topology for HVDC distribution. In this combination, the number of contactors utilised is reduced.

\section{Potential Power Electronic Converter Technologies in MEE}

The choice of power electronic converter technologies for MEE architectures directly affects the design process. The following subsections present candidate power electronic converter technologies for MEE architectures.

\section{- Passive converter}

The Auto-Transformer Rectifier Unit (ATRU) provides unidirectional AC/DC power conversion between the main ac distribution and DC primary distribution. The multi-pulse conversion consists of an auto-transformer and full wave rectifier diode bridges.

\section{- Active converter}

Due to the increased electrification of the systems on the MEE, active power converters may also be employed in the MEE/MEA electrical architecture. The AC/DC and DC/AC converters that are located at generators are used to stabilise the system frequency and output voltage. Separate DC-to-AC inverters can be used for essential passive and motor loads on the engine.

\section{Critical loads in MEE}

In MEE architectures, potential electrical loads include:

- The engine fuel feed system. This would typically include at least one booster pump to draw fuel from the fuel tank, to increase the fuel flow pressure and inject fuel into combustion chamber [4].

- The engine lubrication system. This would typically feature at least one pressure pump to supply engine oil to lubricate mechanical components, several scavenge pumps to return the

Page 4 of 11 
used oil to the oil filter system, and an oil breather pump to clean the used engine oil.

- An electric thrust reverser actuation System (ETRAS). This typically features two upper actuators, two center actuators and two lower actuators [18].

By way of example, the fuel and lubrication systems for a twin-engine commercial aircraft have been estimated to be rated at approximately $75 \mathrm{~kW}$ and $20 \mathrm{~kW}$ respectively [4]. In addition, the full operation ETRAS demand has been estimated at $35 \mathrm{~kW}$ [4].

\section{The Methodology of EPS Reliability Analysis}

System reliability analysis is a critical pre-process stage for the system design and development [19]. It can be perceived as a fundamental safety assessment process for the system design. The analysis performed in this paper predicts numerical failure rates from the estimated system design. Basic component failure rates can be obtained from the public domain or determined from first principles using standard failure rate data handbooks [20].

One particular system reliability analysis method described in SAE ARP4761 [21] is Fault Tree Analysis (FTA). This is considered as a deductive, "top-down" approach [3,18]. FTA is a qualitative model that involves the backwards-stepping process to determine the relationships between the sub-systems (lower levels) and the top event [22]. In terms of FTA, the top event is a system failure event which is the beginning of the fault tree, and is the scenario to be analysed [23].

The main advantage of using the FTA technique is that it displays the system relationships in a structured manner, and is also suitable for the analysis of both large and small systems [24]. Reliability analyses carried out for aircraft systems are often done so with regards to aircraft system failure classifications [3, 20]. These are summarised below.

- Catastrophic failure conditions should be deemed to occur at a rate of less than $1 \times 10^{-9}$ per flight hour. This failure condition is representative of a loss of an aircraft.

- $\quad$ The acceptable maximum rate for hazardous failure conditions is between $1 \times 10^{-7}$ and $1 \times 10^{-9}$ per flight hour. This failure condition represents a significant loss in functionality and safety of aircraft operation.

- The acceptable maximum rate for major failure conditions is between $1 \times 10^{-5}$ and $1 \times 10^{-7}$ per flight hour. The major failure condition results in a significant disruption to aircraft systems and represents a significant increase in operator workload.

- Minor failures are permissible to occur at a maximum rate of between $1 \times 10^{-3}$ and $1 \times 10^{-5}$ per flight hour. These failure types represent a small reduction in system functional capabilities.

In addition, according to the EASA Certification Standard CS-25 [25], essential loads on aircraft should have at least one alternate source of power. This requirement encourages the use of either dual-channel or three-channel architectures for MEE applications.

\section{MEE Architectures Trade Study}

This section presents three trade studies of six MEE EPS architectures, comparing reliability and mass. The first trade study is only focused on busbar topologies (either for HVAC or HVDC) and defines the failure rate associated with the complete loss of power transfer through the busbar. This trade provides the necessary busbar failure rates for the second and third trade study presented as well as giving insight into the unique strengths and weaknesses of each busbar configuration.

The second study presented assesses the rate of complete loss of supply to the HVDC essential engine load bus. This study assumes that each of the concept architectures features generation supplying a 230 VAC bus configuration, which then supplies a downstream HVDC bus, to which the engine loads are connected (similar in concept to the architectures illustrated earlier). The detailed features are described in more detail later.

The third trade study culminates by considering the rate of loss of supply to each and any of the essential engine loads. As a result of the dataset assumptions and simplifications, the study results are representative at this stage, and indeed represent only a small subset of the potential architecture permutations. However, they are still useful in showing the impact of key architectural features on system mass and reliability. The failure rate of each component per flight hour is extracted from [21, 22] and is shown in Appendix 2. The weight of each architecture is also estimated by summing the predicted component weights. Table 3 provides a summary of their key characteristics. The total generators mass was assumed as two geared PM generators and one ungeared PM generator for three-channel architecture design; three ATRUs were considered in each channel of the three-channel system. Likewise, two geared PM generators were implemented in a dual-channel architecture, and two ATRUs for dualchannel EPS.

Table 3. Mass data of electrical components for candidate MEE EPS [12] [26][27]

\begin{tabular}{|c|c|c|c|c|}
\hline Component & $\begin{array}{c}\text { Location of the } \\
\text { architecture }\end{array}$ & Rating & \multicolumn{2}{|c|}{ Mass } \\
Generator & Generation & $250 \mathrm{~kW}$ & $\begin{array}{c}161.2 \mathrm{~kg} \\
\text { (geared) }\end{array}$ & $\begin{array}{c}191.4 \mathrm{~kg} \\
\text { (ungeared) }\end{array}$ \\
\hline \multirow{2}{*}{ ATRU } & $\begin{array}{c}\text { Three-phase } \\
230 \mathrm{~V} \text { ac to } \pm \\
270 \mathrm{~V} \text { dc }\end{array}$ & $250 \mathrm{~kW}$ & \multicolumn{2}{|c|}{$100 \mathrm{~kg}$} \\
\hline \multirow{2}{*}{$\begin{array}{c}\text { Rectifier/ } \\
\text { Inverter }\end{array}$} & $\begin{array}{c}\text { Generation } \\
\text { output to } \\
230 \mathrm{Vac}\end{array}$ & $\begin{array}{c}\text { Feed into load } \\
\pm 270 \mathrm{Vdc} \\
\text { HVDC to } 115 \\
\text { V ac }\end{array}$ & $160 \mathrm{~kW}$ & $28.7 \mathrm{~kg}$ \\
\hline Contactor & Generation bus & $230 \mathrm{Vac}$ & $28.53 \mathrm{~kg}$ \\
\hline Contactor & Load bus & $270 \mathrm{Vdc}$ & $5 \mathrm{~kg}$ \\
\hline CB & Generation bus & $230 \mathrm{Vac}$ & $0.35 \mathrm{~kg}$ \\
\hline CB & Load bus & $270 \mathrm{Vdc}$ & $0.78 \mathrm{~kg}$ \\
\hline
\end{tabular}




\section{Trade Study 1: Loss of Power Transfer through Busbar}

Figure 6 shows the estimated weight and reliability of each of the six busbar arrangement concepts considered. Every busbar layout has a unique probability of failure, which relates to the associated components' failures as well as the limitations of the physical layout. A comparison of busbar arrangements is required to properly characterise this redundancy/failure rate trade.

The six MEE EPS architectures considered were:

- Dual-channel, sectionalised bus configuration

- Dual-channel, ring bus configuration

- Dual-channel, BAAH sectionalised bus configuration

- Three-channel, sectionalised bus configuration

- Three-channel, ring bus configuration

- Three-channel, BAAH sectionalised bus configuration

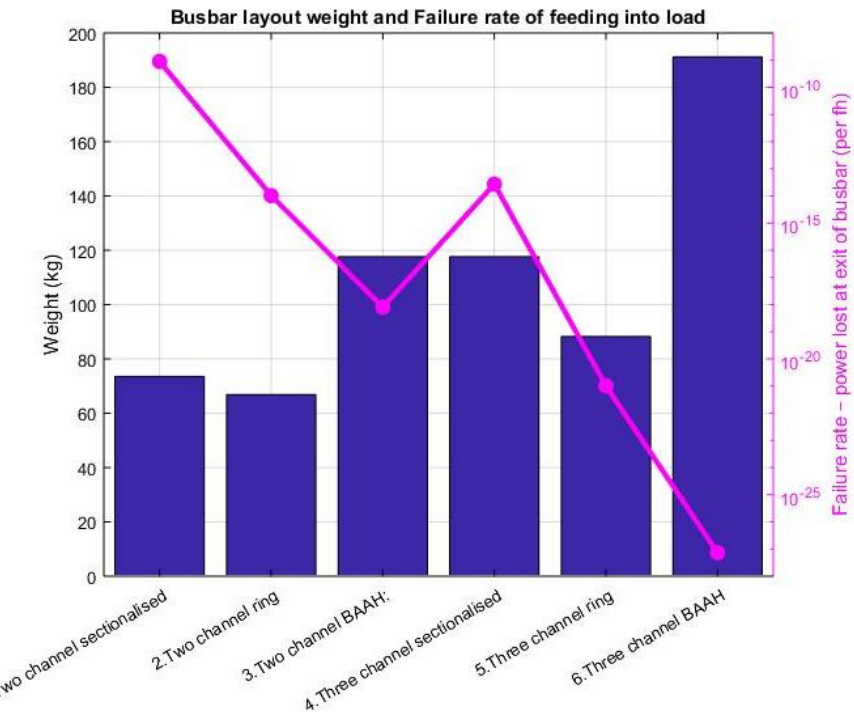

Figure 6. Busbar failure rates and weight

From Figure 6, it can be seen that rate of failure for the loss of supply from the HVAC busbar arrangement lies within the acceptable limits for catastrophic failure for all of the architectures considered. Furthermore, the three-channel BAAH architecture has the lowest rate of failure but is also the heaviest option considered. The increased number of components results in an increased expense while at the same time switch relaying in BAAH may become complicated. The three-channel ring bus architecture has the second lowest failure rate, but is approximately half the weight of the three-channel BAAH architecture considered. In terms of weight, two-channel architectures are understandably all lighter than the equivalent three-channel architectures.

\section{Trade Study 2: Loss of Supply to HVDC Load Bus}

For this case study, failure rates of generators, ATRUs, cables, contactors and an estimated busbar arrangement are accounted for. The Page 6 of 11 top event of this FTA is focused on the catastrophic failure mode of a loss of supply to the HVDC critical load bus, Six architectures were again evaluated, with the results shown in Figure 7. Also, Appendix 1 A shows the example of a dual-channel distribution system FTA.

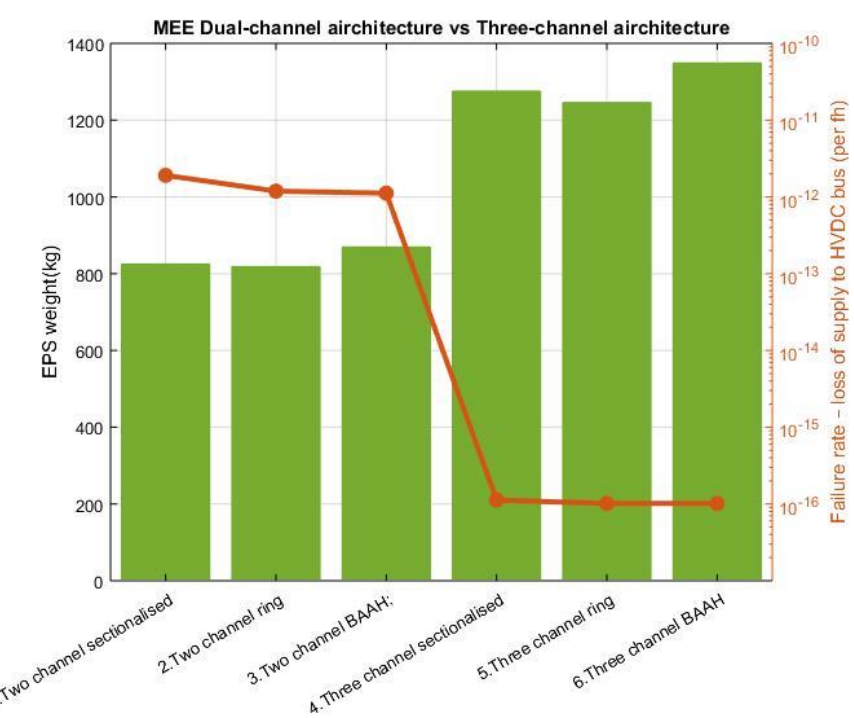

Figure 7. Reliability of power distribution architectures

Because the failure rates of the generator and ATRU dominate the overall system failure rates, there is a less-significant difference between the architecture types, although the effect of the number of channels is notable. Additionally, it can be seen that both dual-channel and three-channel architectures are within the boundaries of the standard failure classification.

\section{Trade Study 3: Loss of Supply to any Critical MEE Load}

For this case study, the top event is the loss of supply to any single critical MEE load. The results of this study are presented in Table 4 and Appendix 1B shows the Fault Tree of a dual-channel MEE EPS with the essential loads in MEE.

The estimated dual-channel load system failure rates for this condition exceed the acceptable rates as defined in CS-25. As a result, the reliability of a dual channel-EPS may require some design improvements. On the other hand, when the load systems are configured within a three-channel EPS, the associated failure rate is more acceptable, although it should be noted that the failure of the loads themselves is still not accounted for. 
Table 4. Essential load failure probability comparison between Dual-channel and Three-Channel architecture

\begin{tabular}{|c|c|c|c|}
\hline \multirow[b]{2}{*}{$\begin{array}{l}\text { Architecture } \\
\text { layout }\end{array}$} & \multirow{2}{*}{$\begin{array}{c}\text { Top event } \\
\text { per flight hour } \\
\text { (one of the } \\
\text { MEE } \\
\text { functions } \\
\text { IFSD caused } \\
\text { by electrical } \\
\text { power system) }\end{array}$} & \multicolumn{2}{|c|}{ Failure rate per flight hour } \\
\hline & & ETRAs & $\begin{array}{c}\text { Oil electric } \\
\text { Pump or } \\
\text { Fuel } \\
\text { electric } \\
\text { Pump }\end{array}$ \\
\hline $\begin{array}{l}\text { Dual-channel } \\
\text { architecture }\end{array}$ & $7.3042 \times 10^{-9}$ & $1.3014 \times 10^{-9}$ & $3.0014 \times 10^{-9}$ \\
\hline $\begin{array}{c}\text { Three- } \\
\text { channel } \\
\text { architecture }\end{array}$ & $1.9939 \times 10^{-13}$ & $4.311 \times 10^{-14}$ & $7.814 \times 10^{-14}$ \\
\hline
\end{tabular}

\section{Conclusion}

This paper has reviewed a range of multi-channel EPS architecture concepts, busbar configurations and associated underpinning technologies. It has provided a quantitative comparison of these architectures in terms of estimated supply failure rates and system mass. Of the architecture concepts considered, ring bus topologies showed a favourable compromise of reliability and mass, whilst three channel configurations appeared to be attractive for attaining high degrees of system reliability. Additional research is required to further explore and tune candidate architecture solutions in order to better accommodate particular equipment reliabilities through careful architecture design, whilst further minimising overall system mass.

\section{Acknowledgements}

This work was carried out as part of the Rolls-Royce University Technology Centre programme.

\section{References}

[1] M. Hirst, A. McLoughlin, P. J. Norman, and S. J. Galloway, "Demonstrating the more electric engine: a step towards the power optimised aircraft," IET Electr. Power Appl., vol. 5, no. 1, p. 3, 2011.

[2] T. I. of E. and Technology, "Rolls-Royce PLC: More Electric Engines for More Electric Aircraft," IET Essent. Eng. Intell. Transp., p. 2, 2013.

[3] Federal Aviation Authority, "Aircraft Electrical System," Aviat. Maint. Tech. Handb. - Airframe, pp. 1-106, 2014.

[4] I. Moir and A. Seabridge, Aircraft systems: mechanical, electrical, and avionic subsystems integration. 2008.

[5] M. Sinnett, "Saving Fuel and Enhancing Operational Efficiencies," Aero Q., pp. 6-11, 2007.

[6] Z. Zhang, J. Li, Y. Liu, Y. Xu, and Y. Yan, "Overview and development of variable frequency AC generators for more electric aircraft generation system," Chinese J. Electr. Eng., vol. 3, no. 2, pp. 32-40, 2017.

Page 7 of 11
P. Wheeler, "The more electric aircraft: Why aerospace needs power electronics?," Proc. 13th Conf. Power Electron. ..., vol. 44, no. 0, 2009.

T. Sawata et al., "Initial Test Results for the Fan Shaft Driven Generator," Power, pp. 1-8.

attery energy storage sytsem integration to the MEA 270V DC power distribution bus using peak current controlled dual active bridge converter," pp. 2068-2073, 2017 .

[12] R. Telford, C. Jones, P. Norman, and G. Burt, "Analysis Tool for Initial High Level Assessment of Candidate MEA Architectures," pp. 1-10, 2016.

[13] J. Brombach, T. Schröter, A. Lücken, and D. Schulz, "Optimized cabin power supply with a / 270 v DC grid on a modern aircraft," 2011 7th Int. Conf. Compat. Power Electron. CPE 2011 - Conf. Proc., pp. 425-428, 2011.

[14] M. B. Stevens and S. Santoso, "Improving the reliability of breaker-and-a-half substations using sectionalized busbars," IEEE Power Energy Soc. Gen. Meet., 2013.

[15] X. Roboam, B. Sareni, and A. De Andrade, "More Electricity in the Air," Ind. Electron. Mag. IEEE, vol. 6, no. 4, pp. 6-17, 2012.

[16] ESRDC, Improving the Reliability of Mvdc Ship Power Systems, no. September. 2013.

[17] D. Nack, "Reliability of substation configurations," Iowa State Univ., pp. 1-19, 2005.

[18] "Brevet de technicien superieur AERONAUTIQUE," 2014.

[19] C. Johansson, On system safety and reliability methods in early design phases. 2013.

[20] Department of Defense of the USA, "Reliability Prediction of Electronic Equipment," Mil. Handb. MIL-HDBK-217F, p. $205,1991$.

[21] M. For, C. The, S. Assessment, P. On, C. Airborne, and T. O. F. Contents, "Aerospace Recommended," Society, pp. 1331, 2012.

[22] Bryant et al., "Fault Tree Handbook with Aerospace Applications," Uma ética para quantos?, vol. XXXIII, no. 8, p. 218, 2002.
D. S. Part and I. D. Features, "Chapter 29 Fault / Success 
Tree Analysis Contents," no. 1, pp. 1-18.

[24]

B. Dhillon, “Fault Tree Analysis,” pp. 214-219, 1999.

[25] EASA, "Certification Specifications for Large Aeroplanes," Cs-25, no. September, p. 750, 2008.

[26] A. Mitcham and J. Cullen, "Permanent magnet generator options for the More Electric Aircraft," Int. Conf. Power Electron. Mach. Drives, no. 487, pp. 241-245, 2002.

[27] “Auto-Transformer Rectifier Units ( ATRU )," p. 15, 1958.

[28] “Möbius tool,” Pisa, Italy.

\section{Contact Information}

The authors are with the Institute for Energy and Environment, Department of Electronics and Electrical Engineering, University of Strathclyde, Technology and Innovation Centre, 99 George Street, Glasgow, UK, G1 1RD. Email; qiyang.zhang@strath.ac.uk

\section{Definitions/Abbreviations}

MEA

More Electric Aircraft

MEE

More Electric Engine
ATRU

HP/LP

HVDC

FADEC

APU

ВАAH

CB

ETRA

PMG

FTA

ESS

IFSD
Auto Transformer Rectifier Unit

High Pressure/ Low Pressure

High Voltage Direct Current

Full Authority Digital Engine Control

Auxiliary Power Unit

Breaker-And-A-Half

Circuit Breaker

Electrical Thrust Reverser Actuation

Permanent Magnet

Generator

Fault Tree Analysis

Energy Storage System

In-flight Shutdown 


\section{Appendix 1A}

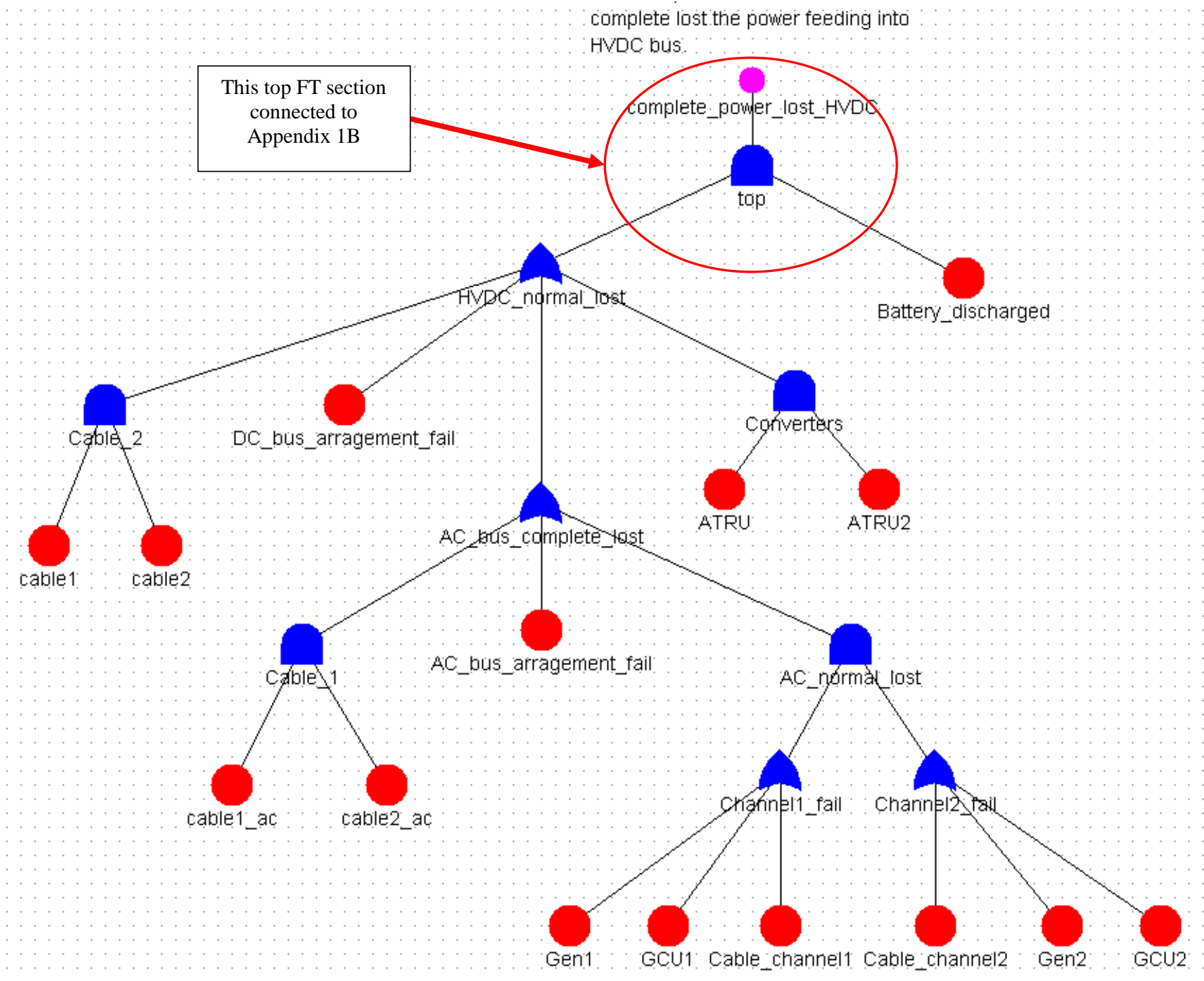

Figure 1A. Fault tree analysis of the distribution system of MEE with a Dual-channel architecture, displayed by Mobius software[28] 


\section{Appendix 1B}

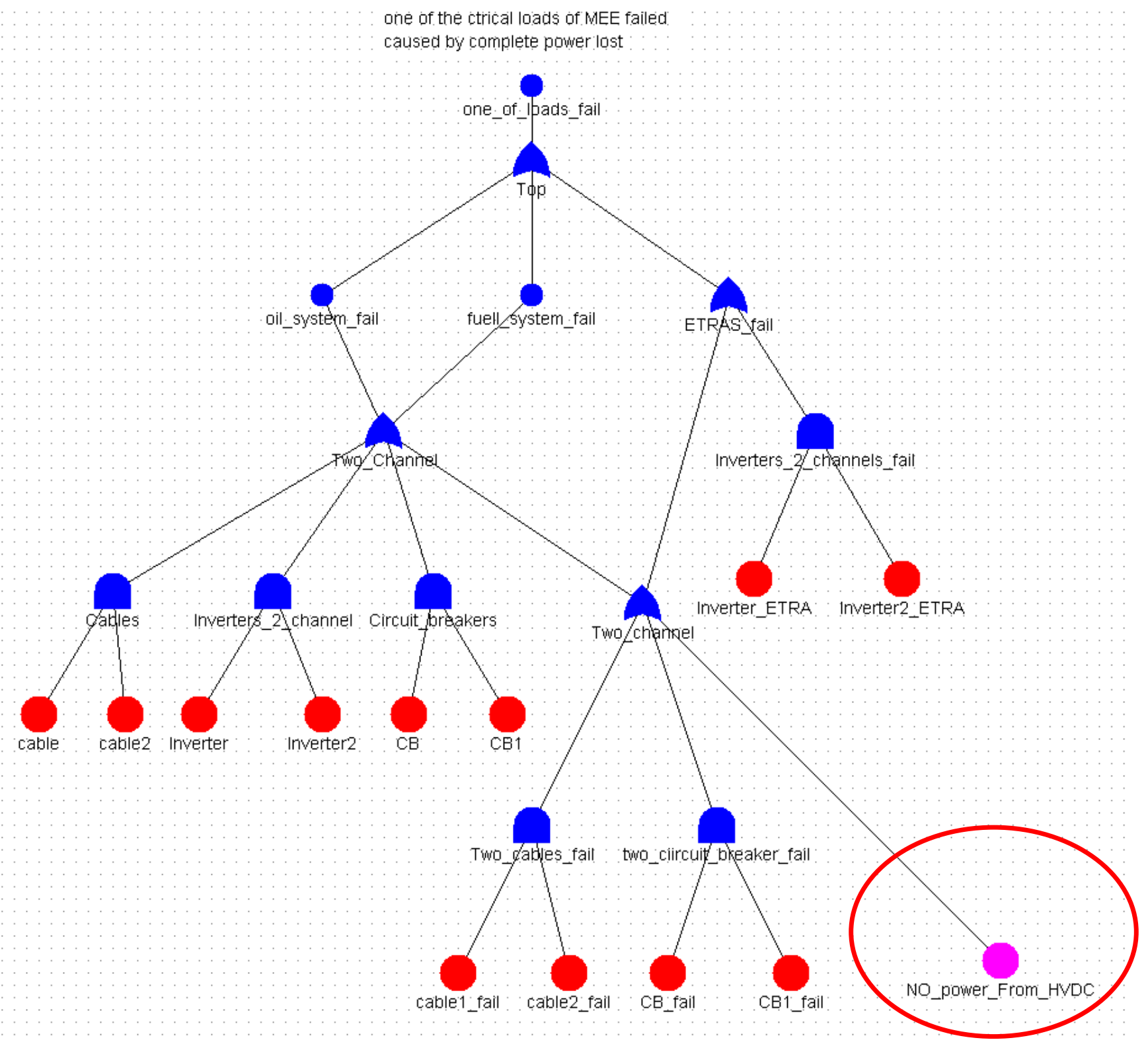

Figure 1B. Fault tree analysis on power flow of the essential loads section of MEE with a Dual-channel architecture, displayed by Mobius software[28]

Page 10 of 11 
Appendix 2

Table A: The component failure rates on a general EPS architecture per flight hour

\begin{tabular}{|c|c|}
\hline Electrical Component & Failure rate per flight hour \\
\hline Generator(VF) & $1.3 \times 10^{-5}$ \\
\hline GCU & $2 \times 10^{-5}$ \\
\hline Cable & $2 \times 10^{-5}$ \\
\hline ATRU/ TRU & $7 \times 10^{-5}$ \\
\hline Battery discharged & $2 \times 10^{-4}$ \\
\hline Busbar & $1 \times 10^{-7}$ \\
\hline Circuit breaker, contactor, switch & $3 \times 10^{-5}$ \\
\hline Rectifier/Inverter & $2 \times 10^{-5}$ \\
\hline Position sensor & $4 \times 10^{-5}$ \\
\hline Control signal & $1.3 \times 10^{-5}$ \\
\hline
\end{tabular}

Page 11 of 11 